\title{
The Semantic Contribution of Wh-words And Type Shifts: Evidence from Free Relatives Crosslinguistically
}

\author{
Ivano Caponigro \\ University of Maryland at College Park
}

\section{Introduction}

Free relatives (henceforth, FRs) are embedded non-interrogative wh-clauses like what Adam cooked in Jie tasted what Adam cooked. They are attested crosslinguistically. So far, I have found them in twenty-eight languages besides English. The main goal of this paper is to show that a crosslinguistic investigation of the semantic behavior of FRs sheds light on the semantic contribution of wh-words and gives further empirical support to the existence of type-shifting rules in the grammar whose purpose is to deal with type-mismatches.

The paper is structured as follows. First, I give a definition of FRs and show their crosslinguistic distribution $(\S 2)$. Then, I move on to investigate their semantic behavior $(\S 3)$. The main conclusion is that FRs follow three different semantic patterns. There are FRs that always exhibit maximality, like definite descriptions ( $\$ 3.2$ ), there are FRs that semantically behave like narrow scope indefinites and never exhibit maximality $(\S 3.3)$, and, finally, there are free relatives that may or may not exhibit maximality ( $\$ 3.4)$.

In the last part of the paper ( $(4)$, I sketch a semantic analysis according to which all FRs denote a set and phrasal wh-words like who, what, where, when, how (and their crosslinguistic equivalents) behave like set restrictors. The different semantic behaviors among the different kinds of FRs result from the presence or the absence of a type-mismatch between the denotation of a FR (i.e. a set) and the semantic requirements of the matrix clause. I argue that, if a type-mismatch occurs, it is repaired by the type shifters iota (l) or existential closure ( $\exists$ ), which Partee (1987), Chierchia (1998), and Dayal (2004) have argued for in order to account for a completely different set of data (i.e. the semantic behavior of DPs like bare plurals and bare singulars).

\section{Introducing Free Relatives}

Let us start by introducing our main character: FRs. The definition of FRs adopted in this work is given in (1). This is meant to be just a working definition, a useful tool to uniquely identify FRs across languages. Examples of FRs in English are given in (2), together with their paraphrases by means of a DP or a PP. So far, I have found FRs in twenty-nine languages from three language families, as summarized in (3). I have collected data directly from native speakers for all of them except for Albanian and Sardinian. The complete set of data can be found in Caponigro (2003). 


\section{(1) Definition of FRs}

FRs are all and only those strings that satisfy the following properties:

a. they contain a wh-word (lexical property); ${ }^{1}$

b. they are embedded clauses with a gap in argument or adjunct position (syntactic property);

c. they can always be replaced with truth-conditionally equivalent DPs or PPs (semantic property).

(2) Examples of FRs in English

a. Jie tasted [FR what Adam cooked].

(cf. Jie tasted [DP \{the food/the thing(s) \} Adam cooked].)

b. I'll marry [FR who you choose].

(cf. I'll marry [DP the person you choose].)

c. You can't smoke [FR where the kids are playing].

(cf. You can't smoke [pp in the place(s) where the kids are playing].)

d. I left [FR when Flavio arrived].

(cf. I left [PP at the same time that Flavio arrived].)

e. WE did it [FR how YOU did it].

(cf. WE did it [Pp in the way YOU did it].)

(3) FRs crosslinguistically

INDO-EUROPEAN:

Germanic: Bavarian, Dutch, English, New York English, Standard

German, Swiss German, West Flemish, Yiddish;

Romance: Catalan, French, Italian, Brazilian Portuguese, European

Portuguese, Romanian, Sardinian, Spanish;

Slavic: Bulgarian, Macedonian, Polish, Russian, Serbo-Croatian, Slovenian;

Albanian, Modern Greek.

FINNO-UGRIC: Estonian, Finnish, Hungarian.

SEMITIC: Modern Hebrew, Modern Moroccan Arabic.

\section{The semantic behavior of FRs}

In this section, I first introduce the notion of maximality as developed by Link (1983) and Jacobson (1995) ( $\$ 3.1)$. Then, I discuss the different semantic behaviors of FRs in which maximality plays a crucial role. Some FRs, which I call DP-like FRs, always exhibit maximality (\$3.2). Some others, which I call existential FRs, never exhibit maximality (§3.3). Finally, what I label PP-like FRs may or may not exhibit maximality (§ 3.4$)$.

\subsection{Maximality}

The notion of maximality that plays a crucial role here is borrowed from Link (1983), who develops it for definite descriptions. I refer to this work for more details and the full formalization. Here I will just try to convey the main intuition 
behind that proposal by means of an example.

In a situation in which Adam cooked an onion (o), a carrot (c), an egg (e), and nothing else, the denotation of a singular NP like thing that Adam cooked would be the set $\{0, c, e\}$ containing the onion, the carrot and the egg, i.e. the set of the atomic individuals that Adam cooked. On the other hand, the denotation of the plural NP things that Adam cooked would be the set containing the plural individuals resulting from all the possible "sums" of the onion, the carrot and the egg, i.e. the set of the plural individuals that Adam cooked $\{\mathrm{e} / \mathrm{c}, \mathrm{c} / \mathrm{o}, \mathrm{e} / \mathrm{o}, \mathrm{e} / \mathrm{c} / \mathrm{o}\}$. A part-of relation (which is reflexive, transitive and anti-symmetric) holds between atomic individuals and the resulting plural individuals. For instance, the two atomic individuals e and c are 'part-of' the plural individual e/c.

Let us now turn to definite descriptions. According to Link, they always denote a maximal individual of a given set, that is the individual that every other individual in the set is a part of. It can be shown that if a maximal individual exists, then it must be unique. In the already familiar situation in which Adam cooked e, c, and o, the plural definite description the things that Adam cooked denotes the maximal individual of the set $\{\mathrm{e} / \mathrm{c}, \mathrm{c} / \mathrm{o}, \mathrm{e} / \mathrm{o}, \mathrm{e} / \mathrm{c} / \mathrm{o}\}$, that is e/c/o. In the current situation, the singular definite description the thing that Adam cooked is undefined, since its NP denotes a set with no maximal individual: $\{0, c, e\}$. On the other hand, if the situation were such that Adam cooked just an egg, then the singular NP thing that Adam cooked would denote a singleton set $\{\mathrm{e}\}$ and the singular definite DP would denote the maximal individual of $\{e\}$, that is e. More generally, a definite description always exhibits maximality, that is it either denotes a maximal individual or is undefined.

With this notion of maximality in hand, we can now turn to the different kinds of FRs and their different semantic behaviors.

\subsection{DP-like FRs}

DP-like FRs are FRs that can always be replaced and paraphrased with a definite DP. They are found in all the languages mentioned in (3) above, except Yiddish. Examples from English are given in (4) together with a DP paraphrase.

a. I want to be hired for [FR what I do as a researcher]/ [DP the work I do as a researcher], not for [FR who I sleep with]/ [DP the (kind of) people I sleep with].

b. [FR Where I went on vacation last year]/ [DP The place I went on vacation last year] was really fabulous.

c. Our first date and [FR when he kissed me for the first time]/ [DP the moment he kissed me for the first time] will stay in my memory forever.

d. You should pay some attention to [FR how she works]/ [DP the way she works]. (Smits 1989: 298, ex. 21).

Jacobson (1995) convincingly shows that DP-like FRs do not exhibit any quantificational force and always trigger maximality, like definite DPs. ${ }^{2}$ She then extends Link's (1983) analysis of definite descriptions to DP-like FRs. I refer the 
reader to Jacobson's work for the details of her analysis. Here I will just give the gist of her intuition by means of an example.

In the already familiar situation in which an egg e was the only thing that Adam cooked, then the DP-like FR what Adam cooked in Jie ate what Adam cooked denotes what the singular definite DP the thing that Adam cooked denotes, i.e. the maximal individual of the set $\{$ e $\}$, i.e. the only entity e. On the other hand, if Adam was a bit hungrier and cooked an egg e, a carrot $\mathrm{c}$ and an onion o, then what Adam cooked in Jie ate what Adam cooked denotes what the plural definite DP the things that Adam cooked denotes, i.e. the maximal individual e/c/o. Therefore, the main difference between a definite DP and a DP-like FR is that the former can carry number morphology (thing vs. things), while the latter does not, since wh-words are semantically unspecified for number, at least in English.

This difference in number morphology has semantic import, according to Link's analysis. As we saw in $\S 3.1$, the set that a definite DP picks up the maximal individual out of contains either only atomic individuals (actually, only one), if the definite DP is singular, or only plural individuals, when the definite descriptions is plural. On the other hand, the set that a DP-like FR chooses the maximal individual from always contains both atomic and plural individuals.

Jacobson gives several arguments to support her claim that DP-like FRs do not exhibit any quantificational force and pattern like definite DPs semantically. Because of space restrictions, I refer the reader to Jacobson's own work. Here I just add one more argument based on quantificational variability effects. Adverbs of quantity (a subset of adverbs of quantification) like for the most part, in part, etc. produce the same truth-conditional effects with DP-like FRs (5)a and definite DPs (5)b,c, while the result of combining adverbs of quantity with indefinite DPs or quantified DPs is truth-conditionally different and often uninterpretable (5)d-g.
a. [FR What you bought] is for the most part expensive.
b. [Definite Plural DP The things you bought] are for the most part expensive.
c. [Definite Mass DP The stuff you bought] is for the most part expensive.
d. \#[Quantified DP Everything you bought] is for the most part expensive.
e. \#[Quantified DP One thing you bought] is for the most part expensive.
f. \#[Indefnite DP Something you bought] is for the most part expensive.
g. \#[Indefinite DP Some stuff you bought] is for the most part expensive.

Although Jacobson concentrates on English DP-like FRs introduced by what, her analysis can be extended to DP-like FRs introduced by other wh-words, as I sketch in (6)-(9). 
(6) who

If I am dating Andrea and Emanuele, then:

a. You are not gonna meet [FR who I am going out with].

b. $\Downarrow_{[\mathrm{FR}}$ who I am going out with $] \diamond=\Downarrow_{[\mathrm{DP}}$ the people I am going out with $] \diamond=$ Andrea $\oplus$ Emanuele

(7) where

If we went to the restaurant Alto Palato last night, then:

a. I really liked [FR where we had dinner last night].

b. $\Downarrow_{[F R}$ where we had dinner last night $] \diamond=\Downarrow_{[D P}$ the place where we had dinner last night $] \diamond=$ Alto Palato

(8) when

If $\mathrm{S}$ is the moment/situation in which he kissed me for the first time, then:

a. Our first date and [FR when he kissed me for the first time] will stay in my memory forever.

b. $\Downarrow_{[\mathrm{FR}}$ when he kissed me for the first time $] \diamond=\Downarrow_{[\mathrm{DP}}$ the moment when he kissed me for the first time] $\diamond=S$

(9) how

If $\mathrm{H} 1$ and $\mathrm{H} 2$ are the ways he behaves when he gets high (e.g. he laughs like an idiot all the time (H1) and does not remember what I just told him (H2)), then:

a. I really hate [FR how he behaves when he gets high].

b. $\Downarrow_{\text {FR }}$ how he behaves when he gets high $] \diamond=\Downarrow_{[D P}$ the ways he behaves when he gets high $] \diamond=\mathrm{H} 1 \oplus \mathrm{H} 2$

To the best of my knowledge, DP-like FRs in all languages that I have found them in so far behave in the same way semantically: they do not exhibit any quantificational force and always denote a maximal individual. Let us now turn to a second kind of FR, existential FRs, and their semantic behavior.

\subsection{Existential FRs}

Existential FRs are all and only FRs that occur in the complement position of existential predicates. They are found in all languages with FRs (see (3)), except English and most other Germanic languages, though Yiddish and a variety of New York English have them. Existential FRs are introduced by the same wh-words that introduce DP-like FRs, as shown by the Hebrew examples in (10). ${ }^{3}$ More crosslinguistic data can be found in Caponigro (2003, to appear) and Grosu (2004). 
(10) a. le-mazali yesh li [FR im mi le-daber] kshe-ani acuva. to-luck-my have to-me with who to-talk when-I sad 'Fortunately, I have somebody to talk to when I am sad.'

b. al tid'ag -- yesh lanu [FR ma li-kro]. don't worry have to-us what to-read 'Don't worry! We have something to read.'

c. eyn li [FR eyfo le-histater] be-mikre xerum. not-have to-me where to-hide in-case emergency 'I don't have a place where I can hide myself in case of danger.'

d. mafti'a she-yesh la [FR matay li-kro sfarim]. surprising that-have to-her when to-read books 'I am surprised she has (some) time to read.'

e. ani micta'er: eyn li [FR eyx la-asot et ze]. I apologize not-have to-me how to-do ACC it 'I am sorry, but I don't have a way to do it.'

Semantically, existential FRs behave like narrow-scope existentially quantified DPs (i.e. indefinites and non-kind-denoting/non-generic bare plurals), at least in three regards. First, unlike DP-like FRs, existential FRs (11)a can never be replaced and paraphrased with definite DPs (11)c, but only with indefinite DPs or non-kind denoting/non-generic bare plurals (11)b. All the examples in (11)-(14) below are from Italian.

a. C'è [FR chi sà dire solo no].

existential FR there's who can.3s say only no

'There are people who say no all the time.'

b. Ci sono [DP (delle) persone che sanno dire solo no]. Indefinite there are (some) people that can.3P say onlyno 'There are people who say no all the time.'

c. ${ }^{*}$ Ci sono [Dp le persone che sanno dire solo no]. Definite there are the people that can.3P say onlyno ('There are the people who say no all the time.')

Second, when existential FRs occur with adverbs of quantity (12), the result is just uninterpretable, like quantified expressions and indefinite DPs and unlike DP-like FRs, as seen in (5). All the examples of existential FRs (12) are fully acceptable without the adverb of quantity in bold. 
a. \# In gran parte ho [con chi parlare] quandosono triste. in great part have.1s with who speak.INF when am sad ('I have most of somebody to talk to when I am sad.')

b. \# In partenon ha [di che parlare alle conferenze]. in part not has of what talk.INF to-theconferences (Partly, he doesn't have anything to say at the conferences.')

c. \# In minima parte non avevo [dove nascondermi] in caso di pericolo.

in very-little part not had.1s where hide.INF in case of danger

('To a small extent, I didn't have a place where I could hide in case of danger.')

Third, existential FRs exhibit the same scopal behavior narrow-scope existentially quantified DPs. For instance, they cannot scope over a quantified matrix subject (13)a-b or matrix negation (14)a-b.

a. Ogni donna aveva [FR chi le curava i bambini]. every woman had who to-her takes-care-of the children

b. Ogni donna aveva [DP qualcuno che le curava i every woman had somebody that to-her takes-care-of the bambini].

children

$\forall>\exists$ : 'Every woman had somebody who took care of her children.'

$* \exists>\forall$ : 'There was a certain person and every woman had that person take care of her kids.'

a. Anna Maria non ha [FR chi le cura i bambini]. Anna Maria not has who to-her takes-care-of the children

b. Anna Maria non ha [DP qualcuno che le cura i Anna Maria not has somebody that to-her takes-care-of the bambini].

children

not> $\exists$ : 'Anna Maria doesn't have anybody that takes care of her children.'

* not> $\exists$ : 'There is a certain person and Anna Maria doesn't have that person take care of her children.

We can now turn to the last kind of FR, PP-like FRs, and their semantic behavior.

\subsection{PP-like FRs}

PP-like FRs are all and only FRs that are introduced by where, when, how, and their cross-linguistic equivalents that can be replaced and paraphrased with a PP. For instance, the bracketed constituent in (15)a is a PP-like FR, since it can be 
replaced and paraphrased with a PP, as in (15)b. On the other hand, the bracketed constituent in (16)a is not a PP-like FR, but a DP-like FR, since it cannot be replaced with a PP (16)b, but rather a DP (16)c.

(15) a. I just went [FR where we had dinner last night].

PP-like FR

b. = I just went [PP to the place where we had dinner last night].

(16) a. I didn't like [FR where we had dinner last night].

DP-like FR

b. $\neq^{*}$ I didn't like [PP at/to the place where we had dinner last night].

c. = I didn't like [DP the place where we had dinner last night].

As for their semantic behavior, PP-like FRs exhibit a split pattern. Some PP-like FRs exhibit maximality, i.e. they can always be replaced and paraphrased with a PP with a definite DP as its complement (cf. (15), (17), (18)).

(17) a. [FR When you say goodbye], I die a little.

b. = [PP On the occasions when you say goodbye], I die a little.

(18) a. WE studied for the final [FR how YOU studied for it], but you did better.

b. = WE studied for the final [PP in the same way YOU studied for it], but you did better.

Some other PP-like FRs do not exhibit maximality, but can be replaced and paraphrased with a PP with a narrow-scope existentially quantified DP as its complement.

(19) For years, I lived ...

... [FR where it never snowed].

... \# [PP in the place(s) where it never snowed]. maximal

... [PP in a place/places where it never snowed]. non-maximal

(20) Captain Kirk went ...

... [FR where no man had gone before].

... \#[PP to the place(s) where no man had gone before]. maximal

... [PP to a place/places where no man had gone before].non-maximal

(21) You said Gennaro has class and office hours every week on Tuesday and Thursday. Do you think I could introduce myself ...

... [FR when he is in for his office hours],...

... \# [PP at the time when he is in for his office hours],... maximal

... [PP at a time when he is in for his office hours],... non-maximal

$\ldots$ if he is not talking to any students? 
Barbara Cook managed to sing that old song ...

... [FR how I've never heard it sung before]. ${ }^{4}$

... \#[pp in the way(s) I've never heard it sung before]. maximal

... [pp in a way I've never heard it sung before]. non-maximal

Like narrow scope indefinites, these PP-like FRs semantically cannot scope over a quantified matrix subject (23) or matrix negation (24).

(23) Every friend of mine wants to live [FR where it never snows].

$=$ Every friend of mine wants to live in a (possibly different) place/places where it never snows]. $(\forall>\exists)$

$\neq$ There is a place, among many others, where it never snows (e.g. LA) and all my friends want to live there. $(\exists>\forall)$

(24) I do not want to live [FR where it never snows].

$=$ I don't want to live in $\{\mathrm{a} / \mathrm{any}\}$ place/places where it never snows. $($ not $>\exists)$

$\neq$ There is a place, among many others, where it never snows (e.g. LA), and I don't want to live there. $(\exists>\forall)$

\subsection{Conclusions about the semantic behavior of FRs and their wh-words}

Before concluding this section, let us summarize our findings about the semantic behavior of FRs and draw some related conclusions about the semantic contribution of wh-words. We saw that there are FRs that do not exhibit any quantificational force and always denote a maximal entity (DP-like FRs). There are other FRs that never exhibit maximality, but always behave like narrow scope indefinites (existential FRs). Finally, there are FRs that either exhibit maximality or behave like narrow scope indefinites (PP-like FRs). Crucially, all kinds of FRs are introduced by the same wh-words. Therefore, the semantic differences between FRs on the one hand cannot be due to wh-words and no quantificational force or maximality can be lexically encoded in the semantic contribution of wh-words.

This is not a trivial conclusion, given what the semantic contribution of wh-words has been assumed to be before. Mainly by looking at wh-interrogatives, it has been argued that wh-words denote sets (Hamblin 1973), or behave like existentially quantified expressions (Karttunen 1977), or are ambiguous between existentially and universally quantified expressions (Hintikka 1976), or trigger maximality like definite descriptions (Jacobson 1995), or, finally, introduce a free variable in the logical representation, like indefinites under certain accounts of indefinites (Nishigauchi 1990; Berman 1994; Ginzburg and Sag 2000). In other words, the entire semantic inventory for DPs has been proposed as the semantic contribution of wh-words. By looking at the semantic behavior of FRs crosslinguistically, we concluded that wh-words cannot lexically encode any quantificational force or maximality, but rather they behave like set restrictors, as I show in the next section. 


\section{Proposal: A semantic analysis for FRs}

In this section, I propose a semantic analysis for FRs that is based on the conclusions in the previous section about the semantic behaviors of the different kinds of FRs and the semantic contribution of wh-words. I begin with some preliminary assumptions that apply to all kinds of FRs ( $\$ 4.1)$. Then, I sketch a compositional semantic analysis for each kind ( $\S 4.2)-(4.5)$.

\subsection{Preliminaries assumptions}

The syntactic nature of FRs is an open problem for current syntactic theory. Are they headed relative clauses with a wh-head or a silent head? Or are they bare CPs? Or do they require our syntactic theory to be enriched with new notions like multi-dominance? Also, do FRs that are semantically different differ at the syntactic level as well? To the best of my knowledge, no final answer to these questions has been given yet. I refer the interested reader to Citko (2000), Grosu (2003) and de Vries (2002) for detailed discussions. Here I assume that all FRs are bare CPs for the sake of simplicity. I believe nothing crucial in my semantic analysis hinges on this assumption. From the semantic point of view, I assume that all FRs denote a set. ${ }^{5}$ I also enrich the ontology by adding entities like places/locations, times/situations, and manners to the usual members of the domain D of the model. Finally, phrasal wh-words are assumed to act as set restrictors: they apply to a set and return a subset (25).

$$
\begin{aligned}
& \text { wh- } \mid \lambda \mathrm{X} \lambda \mathrm{x}[\mathrm{P}(\mathrm{x}) \cdot \mathrm{X}(\mathrm{x})] \\
& \mathrm{P}=\underset{\text { animate }(w h o), \text { inanimate (what), place/location (where), }}{\text { time/situation (when), and manner (how) }}
\end{aligned}
$$

\subsection{A semantic analysis for existential FRs}

We concluded above that existential FRs always occur in the complement positions of existential predicates and behave like narrow-scope existentially quantified expressions semantically. Following Milsark (1977), Szabolcsi (1986), Grosu and Landman (1998), Izvorski (1998), Grosu (2004), I assume that existential predicates select for a set-denoting complement and existentially close it. The set denoted by a FR in the complement position of an existential predicate is existentially closed by the matrix predicate. Since the existential quantifier is part of the lexical meaning of the matrix predicate, it cannot be raised. Therefore, existential FRs always exhibit narrow scope with respect to matrix negation or a quantified matrix subject. An example of a semantic derivation for an existential FR from Italian is given in (26). The crucial steps of the derivation concern the semantic contribution of the existential predicate and the wh-word and are highlighted in bold. 
C'è [FR chi dice sempre sì].

there's who says always yes

'There are people who say yes all the time.'

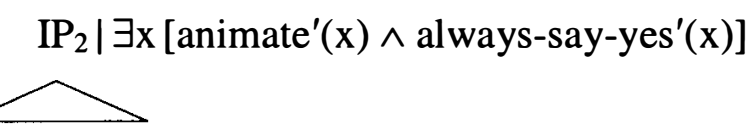

$C^{\prime} \grave{e}$ 'there's' $\lambda \mathbf{P} \exists \mathbf{x P}(\mathbf{x}) \mathrm{CP}_{1} \mid \lambda \mathrm{x}_{1}$ [animate' $\left(\mathrm{x}_{1}\right) \wedge$ always-say-yes' $\left.\left(\mathrm{x}_{1}\right)\right]$

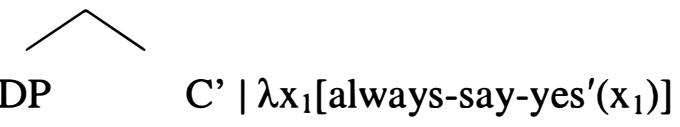

$\operatorname{chi}_{1}{ }^{\prime}{ }^{\prime}$ who'$^{\prime} \mid \lambda \mathrm{X} \lambda \mathrm{x}_{1}\left[\operatorname{animate}^{\prime}\left(\mathrm{x}_{1}\right) \cdot \mathrm{X}\left(\mathrm{x}_{1}\right)\right]$

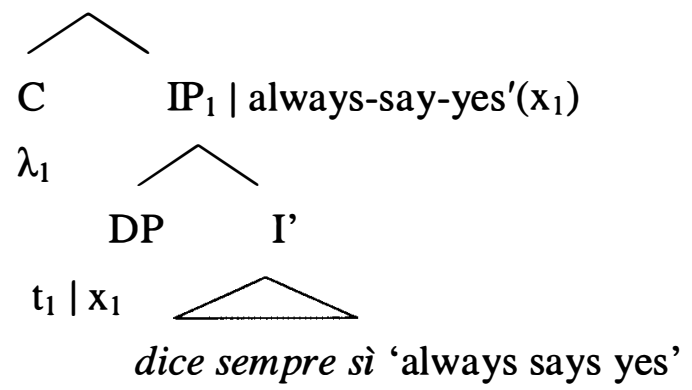

\subsection{A semantic analysis for DP-like FRs}

Partee (1987), Chierchia (1998), and Dayal (2004) have argued that type-shifting rules are made available by the grammar to fix type-mismatches. Among those, iota ( $($ ) applies to a set $\mathrm{P}$ and returns its maximal individual (27).

iota (l): $\mathrm{P} \rightarrow \mathrm{uxP}(\mathrm{x})(<\mathrm{e}, \mathrm{t}>\rightarrow<\mathrm{e}>)$

The empirical evidence for a type-shifting rule like iota that Chierchia and Dayal bring comes from the crosslinguistic behavior of DPs, in particular bare plurals, and bare singulars. For lack of space, I refer the reader to work mentioned above for the data and the details of the proposal. In what follows, I argue that DP-like FRs crosslinguistically bring further evidence in favor of the existence of iota.

We assumed in $\S 4.1$ that all FRs denote a set of individuals (type $<e, t>$ ) to start with. This assumption allows for a simple account of existential FRs, as we saw in $\S 4.2$. On the other hand, in $\S 3.2$, we concluded that DP-like FRs denote a maximal individual (type <e>). How can a set-denoting expression be turned into an individual-denoting one? If DP-like FRs always denote a set, like all other FRs, then a type-mismatch always occurs between their denotation (type $<e, t>$ ) and the semantic requirements of its matrix clause (type <e>). If a type-shifting rule like iota exists in the grammar, the basic set-like denotation of a FR would be predicted to shift into an entity-like denotation by picking up the maximal individual of the initial set. As we saw in $\S 3.2$, this prediction is borne out and correctly accounts for the data.

An example of a detailed semantic derivation for a DP-like FR from Italian is given in (28). Comments follow. 
(28) Detesto [FR chi dice sempre sì].

hate.1s who says always yes

'I can't stand who says yes all the time.'

$\mathrm{IP}_{2}$

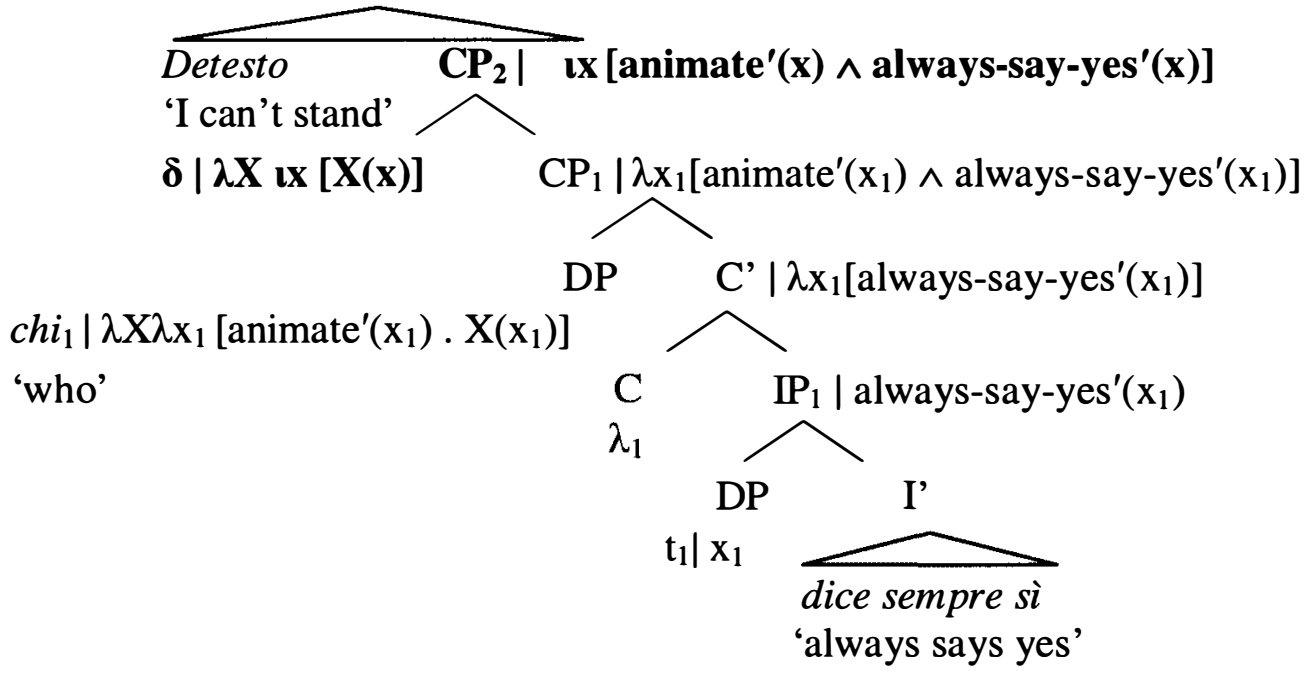

The matrix predicate detesto 'I can't stand' in (28) selects for an individual-denoting expression in its complement position. What one may not stand are individuals, not sets of individuals. ${ }^{6}$ On the other hand, the FR in (28) denotes the sets of individuals that say yes all the time, similarly to what we saw in (26) for the homophonous existential FR. The only difference between the semantic derivation of the sentence with the existential FR in (26) and the one with a DP-like FR in (28) is that a type-mismatch arises between the FR and the matrix predicate in the latter. Therefore, iota is allowed to apply (encoded as the daughter $\delta$ of $\mathrm{CP}_{2}$ in the tree in (28)) and shifts the FR denotation from the set of individuals who say yes all the time to its maximal individual.

\subsection{A semantic analysis for maximal PP-like FRs}

As we saw in $\S 3.3$, there are PP-like FRs that exhibit maximality, i.e. they can be replaced and paraphrased with a PP whose complement is a definite DP. In this section, I show how the assumptions about the semantic contributions of wh-words and type shifters that we have made so far can allow us to account for the semantic properties of maximal PP-like FRs. I do so by discussing the example in (29) and its semantic derivation. 


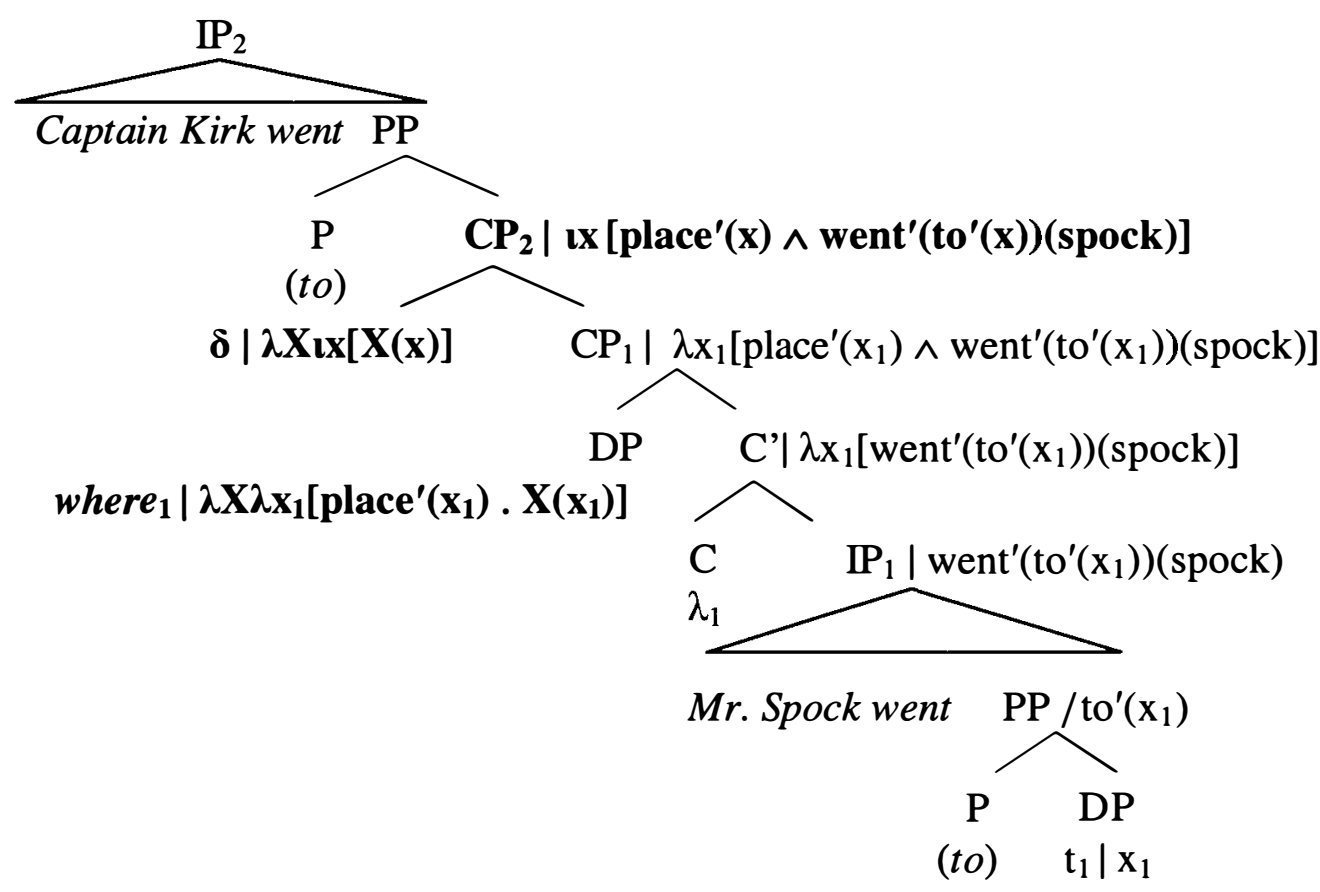

The basic denotation of the PP-like FR in (29), i.e. the denotation of the $\mathrm{CP}_{1}$ node, is a set of individuals, in particular the set of places where Mr. Spock went (remember that I am assuming places/locations to be members of the domain D of individuals; cf. $\S 4.1$ ). But the preposition to or, if you prefer, the complex predicate went-to selects for an expression denoting a singular or plural place (type $<e>$ ), not an expression denoting a set of places (type $<e, t>$ ). Therefore the type-mismatch we have seen for DP-like FRs arises here as well and iota can apply. This is how $\mathrm{CP}_{2}$, i.e. the FR after type-shifting, ends up denoting the maximal place where Mr. Spock went.

Incidentally, I am assuming that the wh-word where is basically a DP that is generated in the complement position of a silent preposition to. Similarly the whole FR $\left(\mathrm{CP}_{2}\right)$ occurs as the complement of another instantiation of the same silent preposition. The main pieces of evidence in favor of this assumption are that 1) there are cases in which both Ps are overtly realized (e.g. I am not from [FR where Luca is from]) and 2) there are FRs introduced by where that fall under the definition of DP-like FRs and can be replaced by DPs (e.g. I really liked [FR where we had dinner last night], cf. I really liked [DP the place where we had dinner last night]).

\subsection{A semantic analysis for non-maximal PP-like FRs}

In $\S 3.4$, we saw that there are PP-like FRs that do not exhibit maximality and behave like existentially quantified expressions. I propose that this is due to the fact that non-maximal PP-like FRs denote a set that lacks a maximal individual, since it contains a virtually infinite number of members. The type shifter iota cannot apply to a set lacking a maximal individual. Therefore the type mismatch 
must be repaired in some other way. Partee (1987), Chierchia (1998), and Dayal (2004) have argued that another type shifter is available in the grammar, called existential closure $(\exists)$, that applies to a set-denoting expression and existentially closes it (30)).

$$
\text { existential closure ( } \exists): \mathrm{P} \rightarrow \lambda \mathrm{Y} \exists \mathrm{x}[\mathrm{P}(\mathrm{x}) \wedge \lambda \mathrm{Y}(\mathrm{x})](<\mathrm{e}, \mathrm{t}>\rightarrow<<\mathrm{e}, \mathrm{t}>\mathrm{t} \mathrm{t})
$$

Dayal (2004) also argues that $\exists$ applies only when iota is blocked. The evidence that these authors bring to support both claims come from the realm of DPs. As we will soon see, FRs bring further evidence. An example of a non-maximal PP-like FR is given in like (31). Comments follow.

$$
\text { Captain Kirk went [FR where no man had gone (before)]. }
$$

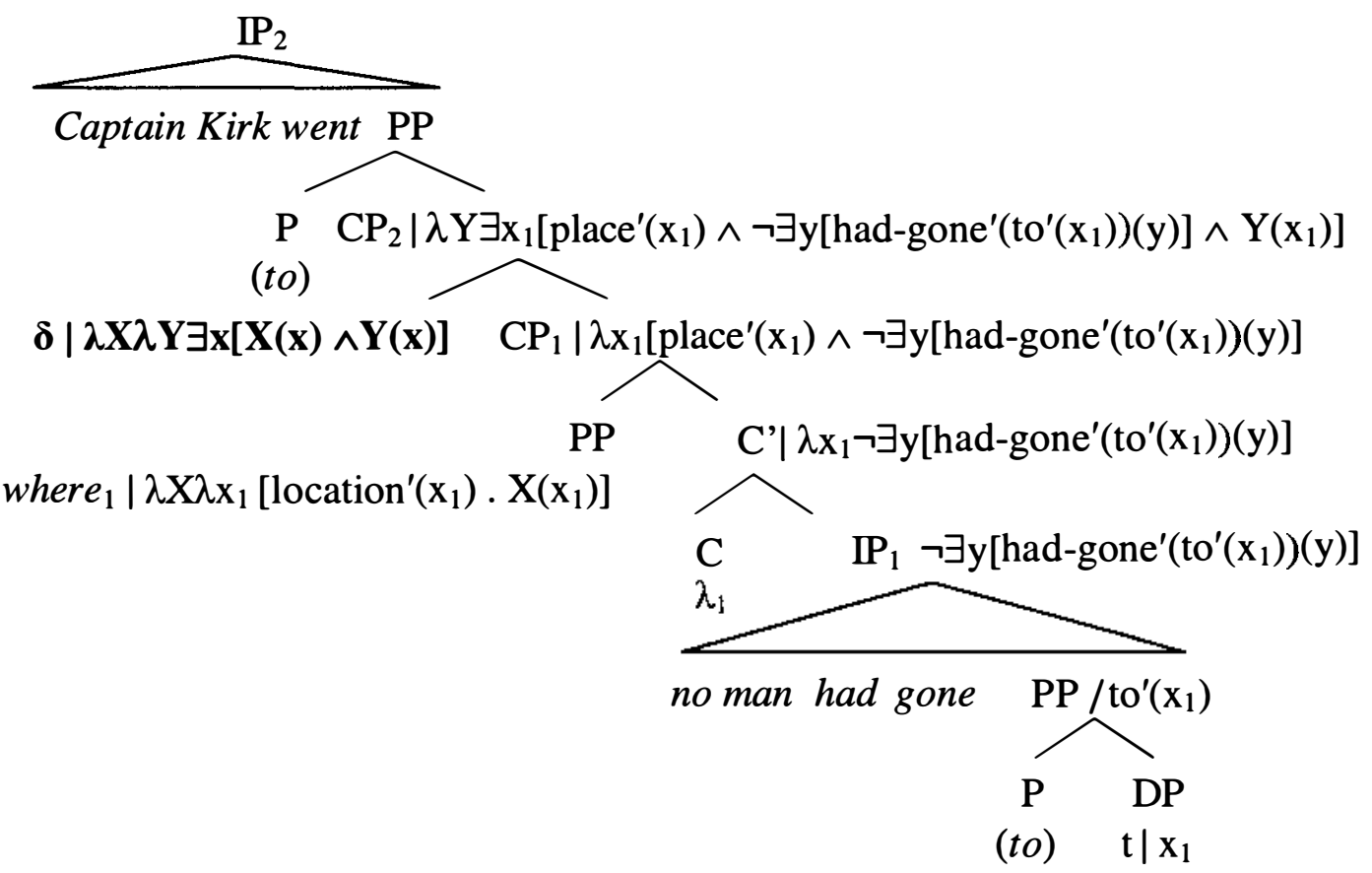

The semantic derivation for the non-maximal PP-like FR in (31) is almost identical to the maximal one in (29) up to the level of $\mathrm{CP}_{1}: \mathrm{CP}_{1}$ denotes a set of places in both sentences. The only crucial difference is that the set denoted by $\mathrm{CP}_{1}$ in (29), i.e. that set of places where Mr. Spock went, is closed and has relatively few members; therefore, the maximal individual is defined for it. On the other hand, the set denoted by $\mathrm{CP}_{1}$ in (31), i.e. the set of the places where no man had gone, is virtually infinite and, as such, lacks the maximal entity. It follows that, although in both sentences there is a type-mismatch between the type requirement of the matrix $\mathrm{P}$ on its complement $(<\mathrm{e}>)$ and the type of $\mathrm{CP}_{1}(<\mathrm{e}, \mathrm{t}>)$, iota can apply and fix it only in (29), but not in (31), since there is no maximal individual in the latter. Therefore, $\exists$ is allowed to apply to the denotation of the $\mathrm{CP}_{1}$ and existentially close it, as in $\mathrm{CP}_{2}$. This accounts for the generalization that non-maximal PP-like FRs never exhibit maximality and behave like existentially quantified expressions. ${ }^{7}$ 


\subsection{Some open issues: non-maximal DP-like FRs and kind-denoting FRs}

As we just saw, there are PP-like FRs that do not exhibit maximality. What about DP-like FRs? Can they not exhibit maximality? The data are not clear. The FR in (32)a, although identical to the PP-like FR in (31), is a a DP-like FR: it can only be replaced and paraphrased with a DP, not a PP. My consultants disagree about the acceptability of (32)a. Those who found (32)a acceptable disagree whether the DP-like FR is better paraphrased with a definite (32)b or an indefinite (32)c.

(32) a. Captain Kirk especially liked [FR where no man had gone before].

b. Captain Kirk especially liked [DP the places where no man had gone before].

c. Captain Kirk especially liked [DP some places where no man had gone before].

In (33)a, a DP-like FR introduced by what is given together with a set that is likely to be open, since there is an almost infinite number of foods that Leston had not tasted before going to Italy and has not tasted yet, even after being in Italy. All my consultants accepted (33)a and most of them, but not all, found (33)c with the bracketed indefinite to a better paraphrase of (33)a than (33)b with the bracketed definite.

(33) a. In Italy, Leston tasted [FR what he had never tasted before].

b. In Italy, Leston tasted [DP the food he had never tasted before].

c. In Italy, Leston tasted [DP some food he had never tasted before].

Further investigation is needed in order to settle this issue. Notice that the account that I proposed for non-maximal PP-like FRs can apply to DP-like FRs as well, as long as they refer to an open set. If it turns out that non-maximal FRs are not attested, then an independent explanation must be found for this fact.

Partee (1987), Chierchia (1998), and Dayal (2004) have argued that another type-shifting rule can apply in the same situation as iota, that is when a type-mismatch occurs involving a set-denoting expression in a position where an individual-denoting expression is selected for: nominalizer. What nominalizer does is, intuitively, to turn a set into its corresponding kind. For instance, it turns the set-denoting NP lions into an expression that denotes the kind lion.

Does nominalizer apply to FRs as well? It is not clear to me what the data show: some FRs can occur in the argument position of predicate selecting for kind-denoting expressions, while some others cannot. For instance, the result of combining a predicate like rare or its Italian equivalent raro with an individual-denoting expression like the name Andrea sounds awkward, while the result sound much better with kind-denoting expressions like that kind of person and its Italian equivalent quell tipo di persona.

(34) a. That kind of person/\#Andrea is rare.

b. Quel tipo di person/\#Andrea è raro. 
FRs behaved in a mixed way with with respect to rare/raro. The English DP-like FR in (35)a can be an argument of rare, but the English DP-like FR in (35)b and the Italian DP-like FR in (35)c sound much less felicitous.

a. [What koalas eat] is really rare.

b. \#[Where it never rains] is really rare.

c. \#[Chi dice sempre sì] è davvero raro. who says always yes is really rare

('He who says yes all the time is really rare.')

I leave this issue open, since I do not have a conclusive answer and I do not think it crucially affects my analysis.

\section{Conclusions}

FRs crosslinguistically exhibit three different semantic behaviors: DP-like FRs always exhibit maximality, existential FRs never do, while some PP-like FRs do, but some others do not. This pattern can be accounted for if we assume that wh-words behave like set restrictors and type shifters like iota and existential closure are available in the grammar. Therefore, a crosslinguistic investigation of the semantic behavior of FRs shows that wh-words do not lexically encode any quantificational force or maximality, unlike what has usually been assumed, and brings new independent evidence in favor of the existence of type-shifting rules in the grammar whose purpose is to deal with type mismatches.

\section{Endnotes}

*Thanks to all my consultants. Special thanks to Veneeta Dayal, Carson Schütze, and Gianluca Storto.

${ }^{1}$ Or a morphologically complex word with a wh-word as its root (e.g. whoever).

2 Actually, Jacobson (1995) argues that what I call DP-like FRs and FRs whose wh-words take the ever suffix behave the same semantically. But Dayal (1997) and Iatridou and Varlokosta (1998) convincingly show that this is not the case. Unlike DP-like FRs, -ever FRs across languages do not exhibit maximality and seem to behave like free choice items (e.g. Jie eats whatever Adam cooks; cf. Dayal 1997) or free adjuncts (e.g. Wherever I go there, it rains; cf. Izvorski 2000)). I refer the interested reader to the works above and the references mentioned therein.

${ }^{3}$ Thanks to Daphna Heller, Orr Ravitz, and Yael Sharvit for the data.

${ }^{4}$ Thanks to Carson Schütze for the example.

${ }^{5}$ I assume FRs to denote plain sets, not singleton sets with a maximal entity as the only member (Jacobson 1995), or lists (Alexiadou and Giannakidou 1998).

${ }^{6}$ If there are three people that you cannot stand, the ontology for plurals that we 
are borrowing from Link (1983) predicts that what you cannot stand is a plural individual resulting from the sum of three atomic individuals, rather than a set of three atomic individuals.

${ }^{7}$ I am assuming different meanings for the two covert Ps in (31). The lowest $P$ takes an individual-denoting complement like the trace $t_{1} /$ variable $x_{1}$, while the highest $\mathrm{P}$ takes $\mathrm{CP}_{2}$, which denotes a function from sets to truth values $(<<e, t>, t>)$. This is not a flaw in our account, but just an instantiation of the more general problem of the semantic treatment of quantified DPs in a non-subject position in a framework like the one that is adopted here. Whatever solution is chosen in order to deal with this problem (e.g. Heim and Kratzer 1998: Ch. 7) will apply to non-maximal PP-like FRs like (31) as well.

\section{References}

Alexiadou, Artemis and Anastasia Giannakidou. (1999). "Specificational pseudoclefts as lists." In K. Shahin, S. Blake, and E. Kim (eds), Proceedings of the Seventeenth West Coast Conference on Formal Linguistics (WCCFL 17), CSLI, Stanford Publications. 1-16.

Berman, Stephen (1994). On the semantics of wh-clauses. New York/London: Garland.

Caponigro, Ivano (to appear). "On the source of maximality in wh-constructions crosslinguistically." Proceedings of the $38^{\text {th }}$ Meeting of the Chicago Linguistics Society (CLS 38).

Caponigro, Ivano (2003). Free Not to Ask: On the Semantics of Free Relatives and Wh-Words Cross-linguistically, Ph.D. Thesis, UCLA.

Chierchia, Gennaro (1998). "Reference to Kinds Across Languages." Natural Language Semantics 6.

Citko, Barbara (2000). Parallel Merge and the Syntax of Free Relatives. Ph.D. thesis, State University of New York at Stony Brook.

Dayal, Veneeta (1997). "Free Relatives and Ever: Identity and Free Choice Readings." Proceedings of SALT VII, 99-116.

Dayal, Veneeta (2004). "Number Marking and (In)definiteness in Kind Terms." Linguistics and Philosophy 27: 393-450.

Ginzburg, Jonathan and Ivan A. Sag (2002). Interrogative investigations. Stanford, California: CSLI.

Grosu, Alexander (2003). "A unified theory of 'standard' and 'transparent' free relatives." Natural Language and Linguistic Theory 21:247-331.

Grosu, Alexander. (2004). "The syntax-semantics of Modal Existential whconstructions." In O. M. Tomić, ed., Balkan syntax and semantics, 405-438. Amsterdam: John Benjamins.

Grosu, Alexander and Fred Landman (1998). "Strange relatives of the third kind." Natural Language Semantics 6:125-170.

Hamblin, Charles L. (1973). "Questions in Montague English." Foundations of Language 10: 41-53. Reprinted in B. H. Partee, ed., 1976, Montague Grammar. 247-259. New York: Academic Press. 
Heim, Irene and Angelika Kratzer (1998). Semantics in Generative Grammar. Oxford, UK: Blackwell.

Hintikka, Jakko (1976). The semantics of questions and the questions of semantics. Amsterdam: North Holland.

Iatridou, Sabine and Spyridoula Varlokosta (1998). "Pseudoclefts Crosslinguistically." Natural Language Semantics 6: 3-28.

Izvorski, R. (2000). "Free adjunct free relatives". Proceedings of WCCFL 19. Somerville MA: Cascadilla Press. 232-245.

Izvorski, Roumyana (1998). "Non-Indicative wh-complements of possessive and existential predicates." In: P.N Tamanji and K. Kusumoto (eds.). Proceedings of NELS 28, 159-173.

Jacobson, Pauline (1995). "On the quantificational force of English free relatives." In: E. Bach, E. Jelinek, A. Kratzer, and B.H. Partee, eds.: Quantification in natural languages, 451-486. Dordrecht: Kluwer.

Karttunen, Lauri (1977). "Syntax and semantics of questions." Linguistics and Philosophy 1:3-44.

Link, Godehard (1983). "The logical analysis of plural and mass terms: A latticetheoretical approach.” In R. Bauerle, C. Schwarze, A. von Stechow, eds., Meaning, use and interpretation of language, 302-323. Berlin: de Gruyter.

Milsark, Gary L. (1977). "Towards an explanation of certain peculiarities of the existential constructions in English.” Linguistics Analysis 3: 1-30.

Nishigauchi, Taisuke (1990). Quantification in the theory of grammar. Dordrecht: Kluwer.

Partee, Barbara H. (1987). "Noun Phrase interpretation and type-shifting principles." In: R. Bauerle, C. Schwarze, and A. von Stechow, Meaning, use, and interpretation of language, 361-383. Berlin: Walter de Gruyter.

Smits, R.J.C. (1989). Eurogrammar.The Relative and Cleft Constructions of the Germanic and Romance Languages. Dordrecht: Foris.

Szabolcsi, Anna (1986). "Indefinites in complex predicates." Theoretical Linguistic Research 2: 47-84.

de Vries, Mark (2002). The syntax of relativization. Utrecht: LOT. 